\title{
Cigarette smoking during pregnancy and preeclampsia risk: a systematic review and meta-analysis of prospective studies
}

\author{
Jun Wei ${ }^{1}$, Cai-Xia Liu ${ }^{1}$, Ting-Ting Gong ${ }^{1}$, Qi-Jun $\mathbf{W u}^{2}$, Lang $\mathbf{W u}^{3}$ \\ ${ }^{1}$ Department of Obstetrics and Gynecology, Shengjing Hospital of China Medical University, Shenyang, China \\ ${ }^{2}$ Department of Clinical Epidemiology, Shengjing Hospital of China Medical University, Shenyang, China \\ ${ }^{3}$ Center for Clinical and Translational Science, Mayo Clinic, Rochester, MN, USA \\ Correspondence to: Qi-Jun Wu, e-mail: wuqj@sj-hospital.org
}

Keywords: cigarette smoking, meta-analysis, preeclampsia, risk factor

Received: August 13, 2015

Accepted: October 06, 2015

Published: October 20, 2015

\section{ABSTRACT}

\begin{abstract}
Although evidence from epidemiological studies evaluating the association between cigarette smoking during pregnancy and preeclampsia risk has been systematically reviewed, the findings have been out of date. To further clarify the relationship, we conducted this comprehensive meta-analysis of prospective studies. We searched PubMed and Web of Science up to August 2015 to identify prospective studies that evaluated the association between cigarette smoking during pregnancy and preeclampsia risk. Random-effects models were used to estimate summarized relative risk (RR) and 95\% confidence intervals (CIs). Seventeen prospective studies involving 62,089 preeclampsia patients from a total of approximately 1.8 million subjects were included. Overall, there was a significant negative association between smoking during pregnancy and incidence of preeclampsia ( $R R=0.67,95 \%$ CI: $0.60-0.75)$, with significant heterogeneity $\left(I^{2}=91.7 \%\right)$. Such an inverse association was also detected in strata of subgroup analyses according to study location, study sample size, parity of populations, singleton pregnancy, and adjustment for potential confounders including maternal age, diabetes mellitus, chronic hypertension, body mass index, and gender of infant. In summary, this meta-analysis suggests that smoking during pregnancy is inversely associated with incidence of preeclampsia. Further large scale multi-center prospective studies are warranted to validate our findings.
\end{abstract}

\section{INTRODUCTION}

Preeclampsia is characterized by either increased blood pressure and proteinuria or exaggerated inflammation of other organs $[1,2]$ and causes complications in 3-5\% pregnancies globally [3], resulting in a large number of cases of morbidity and mortality for mothers and infants [3]. It is categorized into two subtypes according to the timing of onset of disease, early-onset and late-onset preeclampsia, which both represent serious complications $[4,5]$. Although research has shown that genetic, environmental and vascular-mediated factors may jointly play roles in its pathogenesis $[6,7]$, the exact etiology remains unsatisfactorily understood.

Unlike the general knowledge regarding the harmful effects of smoking on health, maternal smoking during pregnancy has been demonstrated to protect potentially from the development of preeclampsia [8]. In vitro and in vivo studies have suggested that antiangiogenic factors may be involved in the pathogenesis of preeclampsia $[9,10]$. Additionally, nicotine may not only reduce the plasma volume by influencing the production of prostaglandins $[11,12]$ but may also reduce the levels of oxidative stress by deregulating the antioxidant systems in the placenta $[13,14]$. During the past several decades, many epidemiological studies have shown that smoking during pregnancy is inversely associated with incidence of preeclampsia [15-28]. Additionally, a dose-response relationship for the duration of smoking and risk of preeclampsia was detected in several studies as well $[18,22,26]$. On the other hand, such a significant association was not detected in several other studies 
[29-32]. England et al. [33] conducted a systematic review of this issue. However, that review did not quantitatively summarize the available evidence to provide an accurate estimation. Although there was a meta-analysis study which provided such a quantitative summary (summarized relative risk $=0.68,95 \%$ confidence interval: $0.67-0.69$ in cohort studies) [34], evidence was summarized only up to 1998, and information from many more updated original studies has not been incorporated [15-25, 29, 30].
An up-to-date comprehensive and quantitative metaanalysis summarizing all evidence is thus critical for more accurately assessing the aforementioned issue. Furthermore, considering that retrospective case-control studies have more severe biases due to their retrospective nature, we thus aimed to carry out the most comprehensive meta-analysis of prospective studies to evaluate systematically the relationship between smoking during pregnancy and risk of preeclampsia.

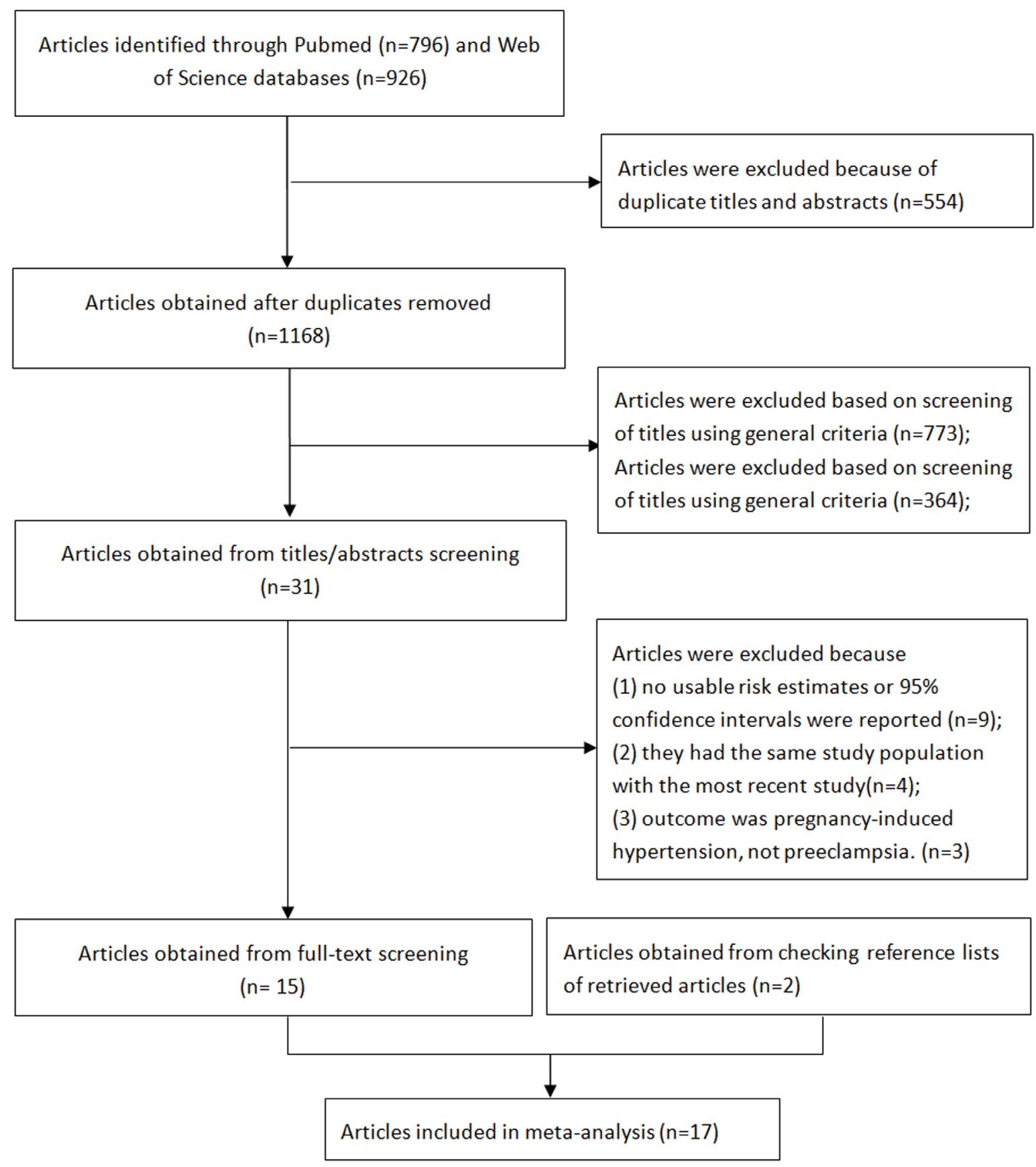

Figure 1: Flow-chart of study selection. 
Table 1: Methodological quality of prospective studies included in the meta-analysis*

\begin{tabular}{|c|c|c|c|c|c|c|c|}
\hline $\begin{array}{c}\text { First author (reference), } \\
\text { publication year }\end{array}$ & $\begin{array}{c}\text { Represen- } \\
\text { tativeness } \\
\text { of the } \\
\text { exposed } \\
\text { cohort }\end{array}$ & $\begin{array}{l}\text { Selection } \\
\text { of the } \\
\text { unexposed } \\
\text { cohort }\end{array}$ & $\begin{array}{c}\text { Ascertain- } \\
\text { ment of } \\
\text { exposure }\end{array}$ & $\begin{array}{c}\text { Outcome of } \\
\text { interest not } \\
\text { present at } \\
\text { start of study }\end{array}$ & $\begin{array}{l}\text { Control for } \\
\text { important } \\
\text { factor or } \\
\text { additional } \\
\text { factor }^{\dagger}\end{array}$ & $\begin{array}{l}\text { Assess- } \\
\text { ment of } \\
\text { outcome }\end{array}$ & $\begin{array}{c}\text { Adequacy } \\
\text { of follow- } \\
\text { up of } \\
\text { cohorts }\end{array}$ \\
\hline Lisonkova et al [15], 2013 & $*$ & $*$ & $*$ & $*$ & $* *$ & $*$ & $*$ \\
\hline Perni et al [16], 2012 & $*$ & $*$ & $*$ & $*$ & $* *$ & $*$ & $*$ \\
\hline Stone et al [17], 2007 & $*$ & $*$ & $*$ & $*$ & $* *$ & $*$ & $*$ \\
\hline Hammoud et al [18], 2005 & $*$ & $*$ & $*$ & $*$ & $* *$ & $*$ & $*$ \\
\hline Ioka et al [29], 2003 & - & $*$ & $*$ & $*$ & - & $*$ & * \\
\hline Basso et al [19], 2003 & $*$ & $*$ & $*$ & $*$ & $* *$ & $*$ & $*$ \\
\hline England et al [30], 2002 & $*$ & $*$ & $*$ & $*$ & $* *$ & $*$ & $*$ \\
\hline Newman et al [21], 2001 & $*$ & $*$ & $*$ & - & $*$ & $*$ & $*$ \\
\hline Mortensen et al [20], 2001 & $*$ & $*$ & $*$ & $*$ & $*$ & $*$ & $*$ \\
\hline Xiong et al [24], 2000 & $*$ & $*$ & $*$ & - & $*$ & $*$ & $*$ \\
\hline Odegard et al [23], 2000 & - & $*$ & $*$ & $*$ & $*$ & $*$ & $*$ \\
\hline Martin et al [22], 2000 & - & $*$ & $*$ & - & - & $*$ & $*$ \\
\hline Lindqvist et al [25], 1999 & $*$ & $*$ & $*$ & $*$ & $*$ & $*$ & $*$ \\
\hline Zhang et al [26], 1999 & $*$ & $*$ & $*$ & $*$ & $*$ & $*$ & $*$ \\
\hline Knuist et al [31], 1998 & $*$ & $*$ & $*$ & $*$ & $*$ & $*$ & $*$ \\
\hline $\begin{array}{l}\text { Cnattingius et al [27], } \\
1997\end{array}$ & $*$ & $*$ & $*$ & $*$ & $*$ & $*$ & $*$ \\
\hline Coonrod et al [28], 1995 & $*$ & $*$ & $*$ & $*$ & - & $*$ & $*$ \\
\hline
\end{tabular}

*A study could be awarded a maximum of one star for each item except for the item Control for important factor or additional factor. The definition/explanation of each column of the Newcastle-Ottawa Scale is available from (http://www.ohri.ca/programs/clinical_epidemiology/oxford.asp.).

${ }^{\dagger}$ A maximum of 2 stars could be awarded for this item. Studies that controlled for maternal age received one star, whereas studies that controlled for other important confounders such as socioeconomic status/education, body mass index received an additional star.

$\$$ A cohort study with a follow-up rate $>70 \%$ was assigned one star.

\section{RESULTS}

\section{Literature search, study characteristics, and quality assessment}

The detailed steps of the literature search and article screening are shown in Figure 1. Briefly, a total of 1168 articles were retrieved after removing duplicates. After screening of titles and/or abstracts using general criteria, 1137 articles were excluded, leaving 31 articles for full text screening. Among them, sixteen articles were further excluded due to the following reasons: i) no usable risk estimates or $95 \%$ confidence intervals were reported; ii) study population duplication; and iii) the outcome was pregnancyinduced hypertension but not preeclampsia. Besides a total of 15 articles retained from the screening, we further identified two eligible articles from checking reference lists of retrieved articles $[19,26]$. Overall, a total of 17 articles were included in the current meta-analysis [15-31].

The detailed characteristics of these included studies are shown in Supplementary Table S1. Overall, nine studies were conducted in Europe [16, 18-20, 22, 23, 25, 27, 31], six in the United States $[15,17,21,26,28,30]$, one in Canada [24] and another in Japan [29]. These studies enrolled 
62,089 patients from a total of approximately 1.8 million subjects. Among these studies, nine reported the risk estimates as odds ratio (OR) [16-21, 23-25], five as relative risk (RR) [26-28, 30, 31], and one as hazard ratio (HR) [15]. The majority of included prospective studies adjusted for maternal age $(n=14)$. Less than half of the studies adjusted for diabetes mellitus $(n=5)$, chronic hypertension $(n=5)$, body mass index $(n=6)$ and gender of infant $(n=3)$.

The information of study quality is summarized in Table 1. Briefly, for representativeness of the exposed cohort, three studies [22, 23, 29] were not assigned a score because the included population came from a single hospital. For outcome of interest not present at the start of study, three studies $[21,22,24]$ were not assigned a score because preeclampsia was presented at the beginning of the studies. For control for important factor or additional factor, nine studies [15-19, 26, 27, 30, 31] were assigned two scores in one column because they adjusted for more than two relevant factors. Therefore, the major issue of included studies might have been the adjustment for potential confounders in their primary analyses.

\section{Smoking during pregnancy and preeclampsia}

After summarizing estimates from all available studies, there was a significant inverse association between smoking during pregnancy and incidence of preeclampsia $(\mathrm{RR}=0.67,95 \% \mathrm{CI}: 0.60-0.75)$, with considerable heterogeneity $\left(I^{2}=91.7 \%, P<0.001\right.$, Figure 2). There was no significant publication bias as

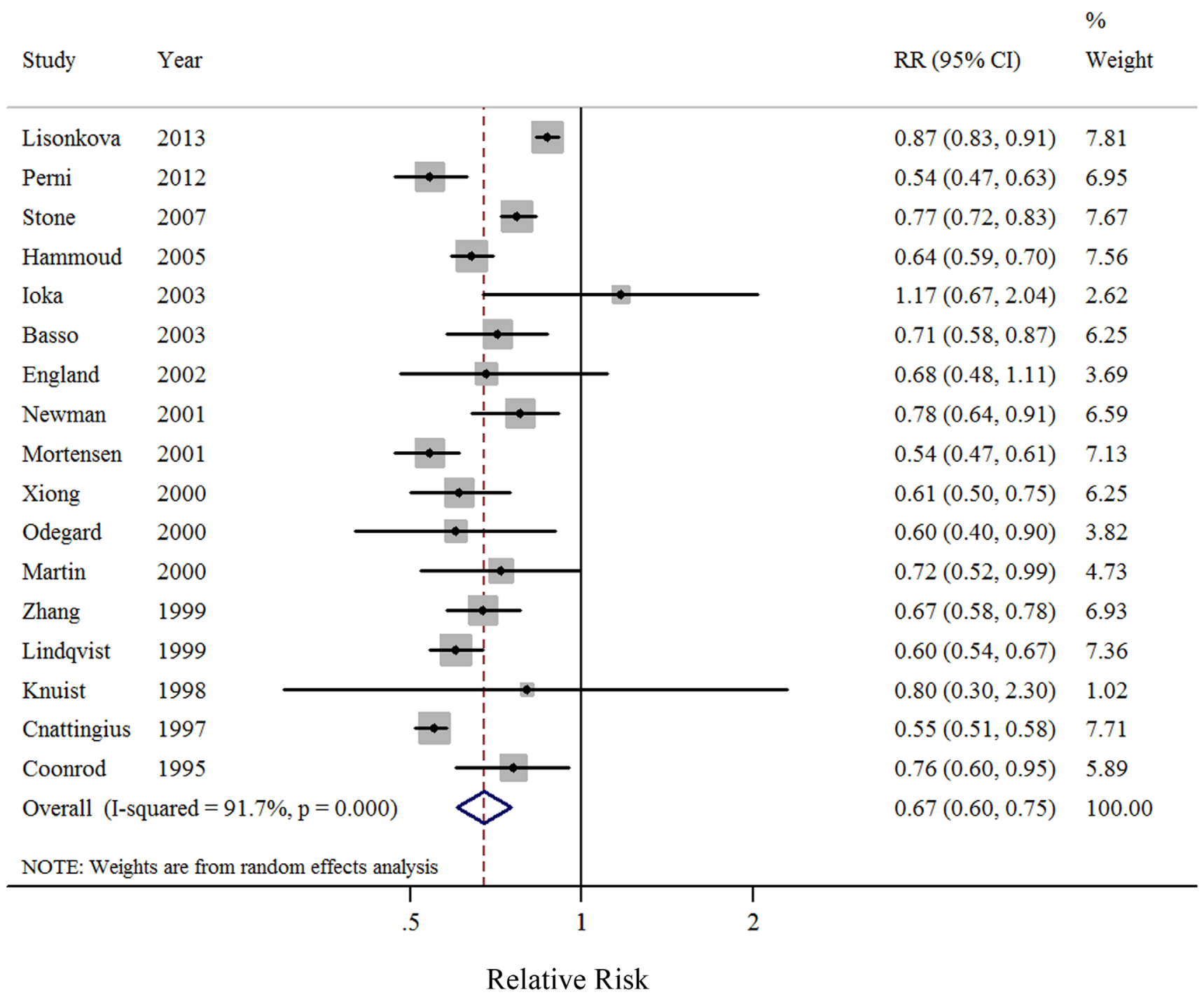

Figure 2: Forest plots (random effect model) of meta-analysis on the relationship between cigarette smoking during pregnancy and incidence of preeclampsia. Squares indicate study-specific risk estimates (size of the square reflects the study-specific statistical weight); horizontal lines indicate 95\% CIs; diamond indicates the summary relative risk with its $95 \%$ CI. $\mathrm{RR}$ : relative risk. 
indicated by Egger's test $(P$ for bias $=0.358)$, Begg's test ( $P$ for bias $=0.232)$, and lack of asymmetry in the funnel plots when inspected visually (Figure 3 ).

\section{Subgroup and sensitivity analyses}

Significant inverse associations were detected in almost all strata of subgroup analyses according to study location, study sample size, parity, type of pregnancy, and adjustment for potential confounders including maternal age, diabetes mellitus, chronic hypertension, body mass index, and gender of infant (Table 2). Notably, the results of meta-regression analyses demonstrated that study location and adjustment for chronic hypertension might have been the source of heterogeneity of the evaluated association. The observed association was stronger among studies in Europe compared with studies in the U.S. Similarly, the summarized estimates were significantly different in studies stratified by adjustment for chronic hypertension $(P=0.002)$.

According to the sensitivity analysis by omitting one study at a time, the summarized RRs ranged from 0.65 (95\% CI: $\left.0.60-0.71, I^{2}=79.8 \%\right)$ after excluding the study by Lisonkova et al. [15] to 0.69 (95\% CI: $0.61-0.77$, $\left.I^{2}=91.5 \%\right)$ after excluding the study by Mortensen et al. [20] (Figure 4). Additionally, when we excluded three studies [22, 28, 29] that provided the crude estimates without adjustment for any potential confounders, the summarized risk estimates remained similar $(\mathrm{RR}=0.66$, 95\% CI: $0.58-0.74, I^{2}=93.1 \%$ ). Furthermore, considering that the incidence rate of preeclampsia is relatively high in some included studies $[21,22,29]$, we used the method proposed by Zhang et al. [35] to convert the RRs into ORs for the summarized analysis, and the result indicated that our finding was robust (summarized OR $=0.67,95 \%$ CI: $0.60-0.75, I^{2}=92.1 \%$ ).

\section{DISCUSSION}

Considering the huge public health burden of preeclampsia as well as the lack of a summary of all available evidence on the relation between smoking during pregnancy and the incidence of this disease, we carried out this comprehensive systematic review and meta-analysis of prospective studies. Overall, the risk of preeclampsia decreased by $33 \%$ among women who ever smoked during pregnancy. Significant inverse associations were also observed in almost all strata of subgroup analyses.

Although the exact mechanism responsible for the relationship between smoking during pregnancy and incidence of preeclampsia is not completely understood, several potential biological mechanisms have been put

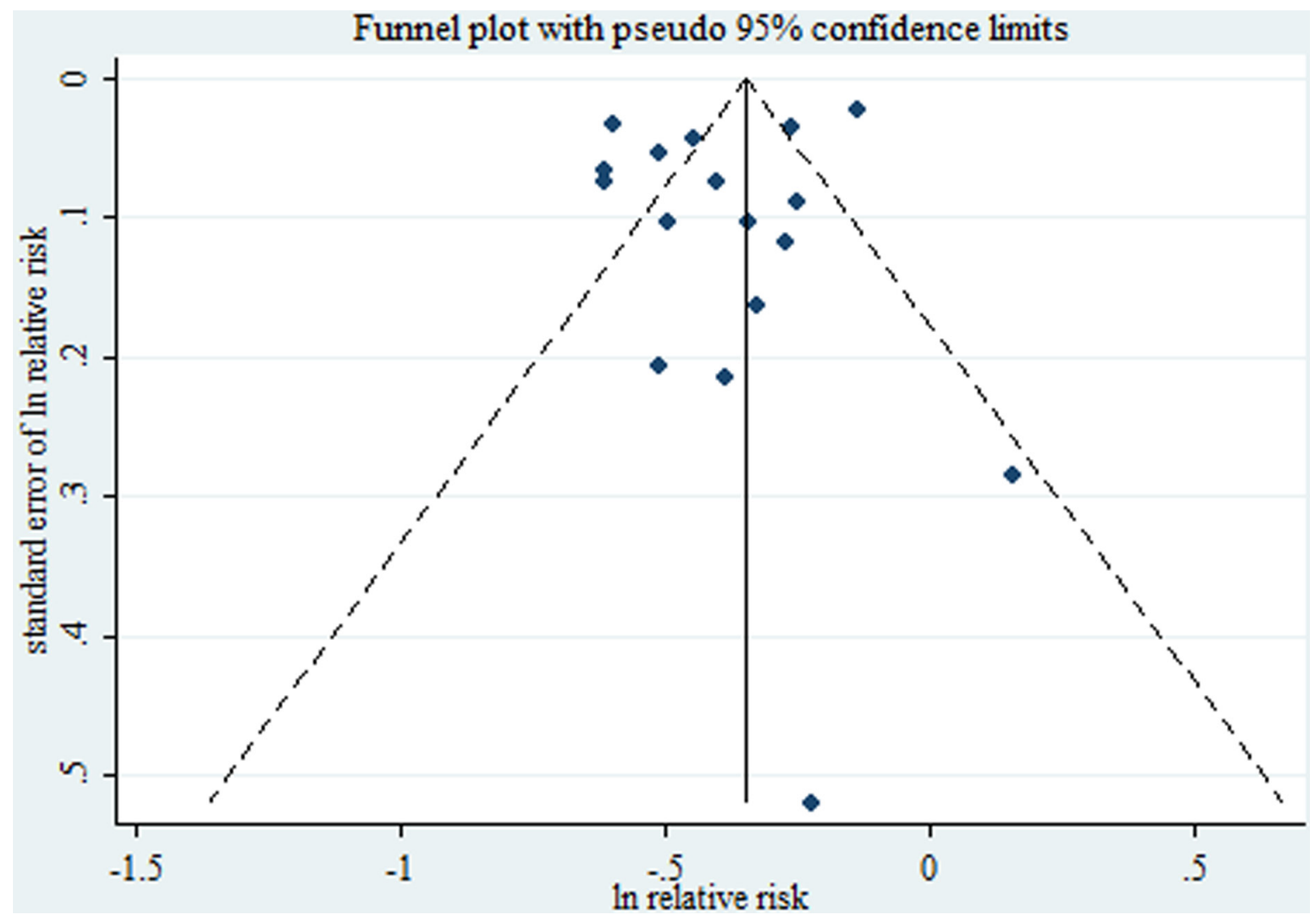

Figure 3: Funnel plot corresponding to the random-effects meta-analysis of the relationship between cigarette smoking during pregnancy and preeclampsia risk. 
Table 2: Summary risk estimates of the associations between smoking and preeclampsia risk

\begin{tabular}{|c|c|c|c|c|c|c|}
\hline & $\begin{array}{l}\text { No. of } \\
\text { studies }\end{array}$ & $\begin{array}{c}\text { Summarized } \\
\text { RR }\end{array}$ & $95 \% \mathrm{CI}$ & $I^{2}(\%)$ & $\boldsymbol{P}^{\dagger}$ & $\boldsymbol{P}^{*}$ \\
\hline Overall & 17 & 0.67 & $0.60-0.75$ & 91.7 & $<0.01$ & \\
\hline Quality assessment & & & & & & 0.90 \\
\hline $\operatorname{High}(\geq 9)$ & 9 & 0.67 & $0.58-0.79$ & 95.0 & $<0.01$ & \\
\hline Low $(<9)$ & 8 & 0.66 & $0.58-0.75$ & 64.9 & 0.01 & \\
\hline Study location ${ }^{\S}$ & & & & & & $<0.01$ \\
\hline North America & 7 & 0.75 & $0.68-0.83$ & 77.0 & $<0.01$ & \\
\hline Europe & 9 & 0.59 & $0.55-0.64$ & 50.2 & 0.04 & \\
\hline Population size & & & & & & 0.18 \\
\hline$<20000$ & 8 & 0.72 & $0.66-0.79$ & 0 & 0.57 & \\
\hline$\geq 20000$ & 9 & 0.64 & $0.55-0.74$ & 95.7 & $<0.01$ & \\
\hline Parity of study population & & & & & & 0.17 \\
\hline Primiparas & 5 & 0.70 & $0.63-0.76$ & 0 & 0.56 & \\
\hline Multiparas & 3 & 0.61 & $0.51-0.74$ & 23.0 & 0.27 & \\
\hline Singleton pregnancy & & & & & & 0.29 \\
\hline Yes & 12 & 0.66 & $0.58-0.75$ & 93.7 & $<0.01$ & \\
\hline No & 5 & 0.75 & $0.63-0.88$ & 1.4 & 0.40 & \\
\hline \multicolumn{7}{|c|}{ Adjustment for potential confounders } \\
\hline Maternal age & & & & & & 0.17 \\
\hline Yes & 12 & 0.66 & $0.58-0.74$ & 93.2 & $<0.01$ & \\
\hline No & 3 & 0.79 & $0.65-0.96$ & 13.9 & 0.31 & \\
\hline SES/Education & & & & & & 0.93 \\
\hline Yes & 6 & 0.67 & $0.55-0.82$ & 96.7 & $<0.01$ & \\
\hline No & 11 & 0.66 & $0.60-0.72$ & 53.3 & 0.02 & \\
\hline Diabetes mellitus & & & & & & 0.68 \\
\hline Yes & 5 & 0.68 & $0.58-0.81$ & 94.5 & $<0.01$ & \\
\hline No & 12 & 0.65 & $0.59-0.72$ & 68.0 & $<0.01$ & \\
\hline Chronic hypertension & & & & & & $<0.01$ \\
\hline Yes & 5 & 0.80 & $0.73-0.88$ & 64.2 & 0.03 & \\
\hline No & 12 & 0.62 & $0.58-0.67$ & 62.8 & $<0.01$ & \\
\hline Body mass index & & & & & & 0.51 \\
\hline Yes & 6 & 0.63 & $0.58-0.69$ & 25.3 & 0.24 & \\
\hline No & 11 & 0.69 & $0.60-0.80$ & 94.2 & $<0.01$ & \\
\hline Infant's sex & & & & & & 0.68 \\
\hline Yes & 3 & 0.69 & $0.51-0.92$ & 95.7 & $<0.01$ & \\
\hline No & 14 & 0.66 & $0.60-0.73$ & 82.1 & $<0.01$ & \\
\hline
\end{tabular}

$\mathrm{CI}$, confidence interval; N/A, not available; RR, relative risk; SES, socioeconomic status.

${ }^{\dagger} P$ value for heterogeneity within each subgroup.

${ }^{\ddagger} P$ value for heterogeneity between subgroups with meta-regression analysis.

${ }^{\S}$ Excluding one study from Japan.

forth, partly explaining this inverse association. Previous studies found that antiangiogenic factors such as soluble fms-like tyrosine kinase 1 (sFlt1; also known as soluble vascular endothelial growth factor receptor-1) and soluble endoglin (sEng) levels may play an important role in the pathogenesis of preeclampsia [9, 10]. In experimental studies, carbon monoxide, one of the main toxic chemicals of smoking, lowers sFlt1 and soluble endoglin production in endothelial cells and placental cultures through the heme oxygenase-1/carbon monoxide pathway [36]. Several studies have also suggested that non-smokers have a higher circulating level of sFlt1 
than do cigarette smokers during pregnancy [10, 37]. Nicotine may reduce the plasma volume by influencing the production of prostaglandins, which are known to be vasoconstrictors $[11,12]$. Furthermore, since antioxidant systems in the placenta are found to be deregulated among smoking women, the reduced levels of oxidative stress may result in a reduction in preeclampsia [13, 14]. On the other hand, there is a possibility that smoking can lead to preterm delivery thus decreasing the incidence of preeclampsia $[17,38,39]$. These understandings are well aligned with our finding that smoking during pregnancy can be inversely associated with preeclampsia risk.

The results of the meta-regression analysis demonstrated that study location might have been a source of heterogeneity $(P=0.025)$. Although significant inverse associations for ever exposure to cigarette smoking during pregnancy with preeclampsia risk were observed in the studies from the U.S. and Europe, the effect estimate based on studies carried out in the U.S. was slightly weaker than that in Europe. This pattern could have been partly attributed to a different prevalence of cigarette smoking during pregnancy among different populations. The average cigarette smoking rates in these included studies were 21.7 and $25.5 \%$ for the U.S. and Europe, respectively. However, there is little discrepancy in the mean incidence rates of preeclampsia between these two locations (5.4\% for U.S. versus 5.1\% for Europe).

Our study has several strengths. First, to the best of our knowledge, this study provided evidence of the relationship between smoking during pregnancy and preeclampsia risk on the basis of the most updated cohort studies, which was the main difference from the previous meta-analysis. Second, our meta-analysis included 17 cohort studies involving 62,089 patients from a total of approximately 1.8 million participants, which provided sufficient power to detect modest associations. Third, because of the prospective design of all included studies, the influence of several biases including recall bias and selection bias could be minimized which resulted in the high quality of these included studies. Furthermore, numerous subgroup analyses according to study characteristics and adjustment for potential confounders suggested that our findings were robust.

Several potential limitations must be acknowledged for our findings. First, we could not fully rule out the possibility of residual confounding because of the nature of observational studies. Although 14 of the 17 included studies provided adjusted estimates

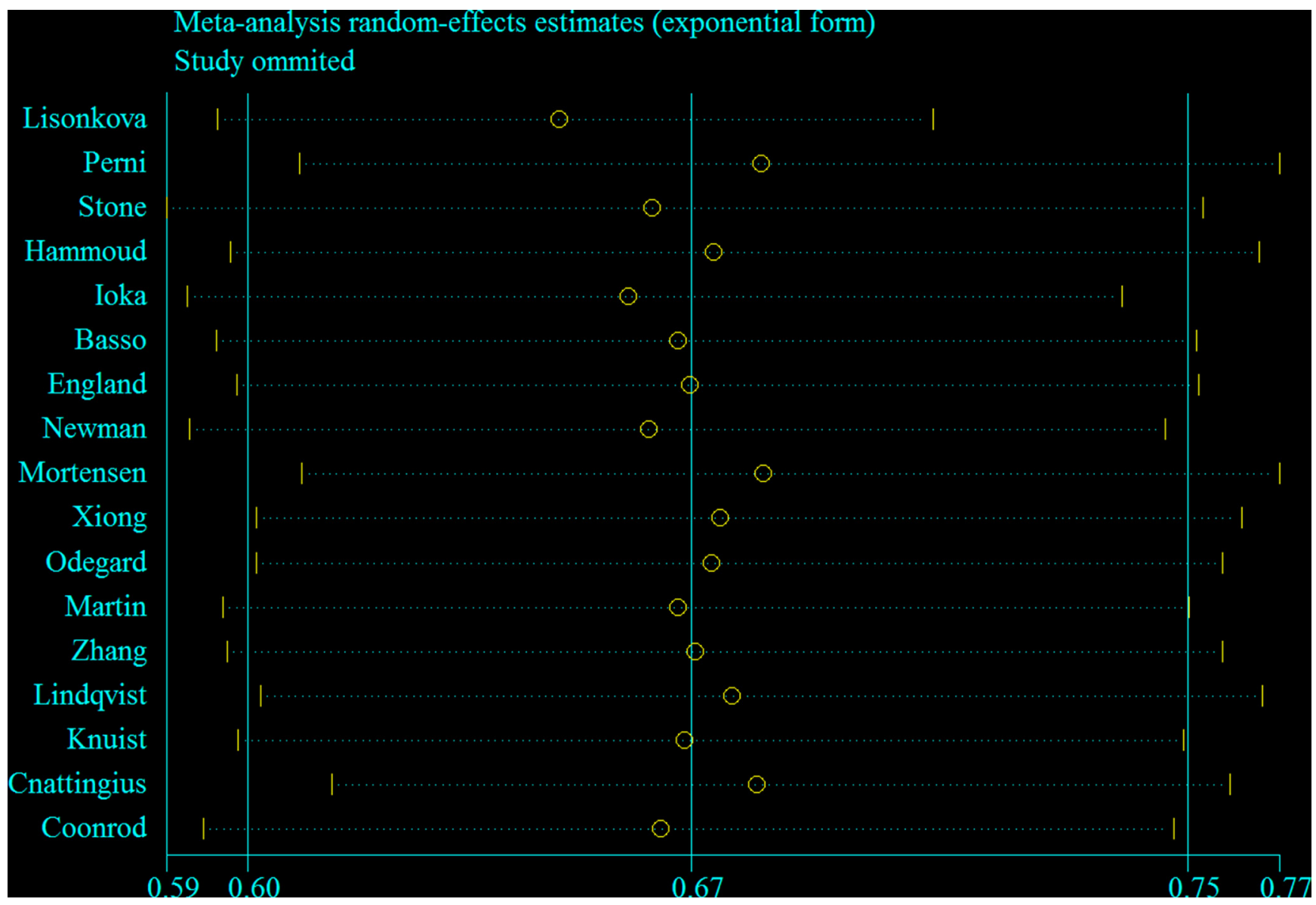

Figure 4: Sensitivity plot corresponding to the relationship between cigarette smoking during pregnancy and preeclampsia risk. 
considering potential confounders, only the variable maternal age was regularly adjusted in the majority of included studies $(n=14)$. Among the 14 studies, nine adjusted for more than two important factors in their primary analyses. Even though the significant inverse associations persisted in all strata of subgroup analyses according to adjustment for potential confounders, the meta-regression analyses demonstrated that whether there was adjustment for chronic hypertension might have been the source of heterogeneity, though we could not rule out the possibility that this result was a chance finding because only 5 studies adjusted for this potential confounder. Furthermore, Perni et al. [16] indicated that maternal mood, anxiety disorders as well as partner change may confound the association between smoking during pregnancy and preeclampsia risk. However, only one included study [18] adjusted for part of these factors in the primary analyses. Since we did not have access to the primary data of these included studies, further pooled analysis is warranted to fully adjust for the potential confounders or report analyses stratified by these possible risk factors to rule out potential residual confounding. Second, significant heterogeneity could be a concern when interpreting the findings of this study. Although numerous subgroup and sensitivity analyses were carried out, heterogeneity still existed in our study. We performed a Galbraith plot to visualize these studies that could have generated the heterogeneity (Figure 5). After excluding seven studies [15-18, 20, 25, 27] from the scale of this plot, significant association persisted and there was no more heterogeneity $\left(\mathrm{RR}=0.70,95 \% \mathrm{CI}: 0.65-0.76, I^{2}=0 \%\right)$. Third, self-reported smoking during pregnancy may result in misclassification. This kind of misclassification may also widely exist in relevant studies, since females tend to change behaviors during early stage of pregnancy while the change may not be accurately captured in those studies [16, 24, 27, 29, 30]. England et al. [40] suggested that self-reported smoking habits of pregnant women may confer an exposure misclassification as high as $21.6 \%$ [16]. The study reported by George et al. [41] indicated that self-reported smoking lacked validity among women who stated that they recently had stopped smoking. Furthermore, only three included studies [23, 25, 26] carried out dose-response analysis, which restricted the possibility to evaluate the hypothesis that heavy smokers might have decreased risk of preeclampsia. Additionally, whether the aforementioned associations could be observed among past smokers needs further investigation.

In summary, the results of this most updated meta-analysis of prospective studies add to the weight

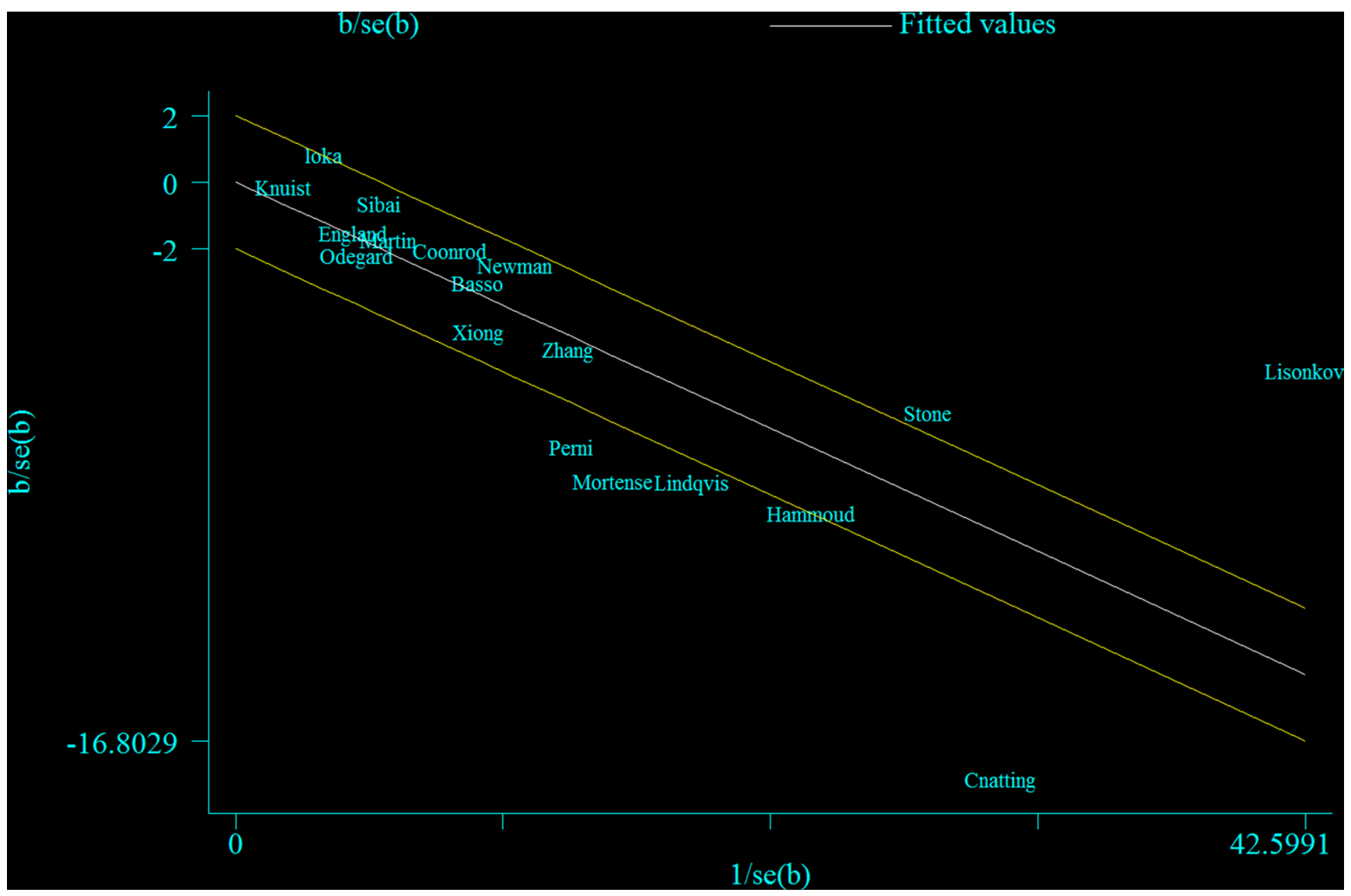

Figure 5: Galbraith plot corresponding to the random-effects meta-analysis of the relationship between cigarette smoking during pregnancy and preeclampsia risk. 
of evidence suggesting that cigarette smoking during pregnancy is inversely associated with preeclampsia. Further prospective studies are warranted to adjust fully for potential confounders and to provide more detailed results stratified by smoking status and subtypes and severity of preeclampsia. Moreover, since the effective treatments of this disease are still lacking, more in vivo or in vitro studies are needed to understand the exact biological mechanisms of this aforementioned association which may contribute to identifying the appropriate therapeutic strategies.

\section{MATERIALS AND METHODS}

\section{Search strategy}

A comprehensive literature search of PubMed (MEDLINE) and Web of Science databases was conducted from each database's inception to August 2015 for relevant studies. We used the following search keywords: (smoking OR tobacco OR cigarette) AND preeclampsia AND pregnancy. We also screened references of relevant review articles and included studies to identify other potential studies [42-45]. This meta-analysis was planned, conducted, and reported in adherence to the Meta-analysis Of Observational Studies in Epidemiology (MOOSE) guidelines [46].

\section{Study selection and exclusion}

Published studies were eligible if they met the following criteria: (i) they were prospective studies; (ii) they clearly defined preeclampsia as gestational hypertension and proteinuria; (iii) they evaluated the association between smoking during pregnancy and preeclampsia risk; and (iv) they presented relative risk (RR), odds ratio (OR), or hazard ratio (HR) estimates with $95 \%$ confidence intervals (CIs) or necessary data for determination. There was no restriction for sample size and follow-up duration. If several publications involved overlapping individuals, we included the study with the most patients.

Published studies were excluded for the following reasons: (i) they were non-epidemiological studies, retrospective studies, reviews without original data, ecological studies, editorials, or case reports; (ii) they reported risk estimates that could not be summarized (such as risk estimates without $95 \%$ CIs); and (iii) they reported the outcome as pregnancy-induced hypertension instead of preeclampsia.

\section{Data abstraction and quality assessment}

A pair of investigators (JW and Q-JW) independently carried out the abstract screening, full-text screening, and data extraction. Disagreements were resolved by discussion. Data extracted from each study included: last name of the first author, publication year, study location, study period, characteristics of study population (sample size, parity information, and singleton or twin pregnancy categories), and effect sizes of the associations (including adjusted confounders information if applicable). If there were multiple estimates for the association, we used the estimate adjusted for the most appropriate confounding variables, like in previous studies [47, 48]. In situations when only unadjusted estimates were given, we used the unadjusted estimates.

To assess the methodological quality of all included studies, the Newcastle-Ottawa Scale (NOS) [49-53] was used in this meta-analysis. As we mentioned in previous studies [42, 48], since quality scoring may not only submerge important information by combining disparate study features into a single score but may introduce somewhat arbitrary subjective elements into the analysis [54-56], we evaluated these included studies on the basis of NOS instead of scoring them and categorizing them into high or low quality according to the scores.

\section{Statistical analysis}

For studies that presented risk estimates separately by the subtype of preeclampsia [15], severity of preeclampsia [27], datasets [25], and status of parity [19], the fixed-effects model [57] was used to summarize the estimates to a combined estimate before incorporating it into the overall summarizing analysis. For studies that did not provide the exact risk estimates for ever versus never exposure to smoking during pregnancy $[25,26]$, we used the effective-count method proposed by Hamling et al. [58] to recalculate the risk estimates. We used $I^{2}$ to evaluate the heterogeneity across studies, in which $I^{2}>50 \%$ suggests high heterogeneity and $I^{2} \leq 50 \%$ suggests low heterogeneity [59]. We summarized log-transformed RR using the random-effects model [60]. To investigate possible sources of heterogeneity of main findings, subgroup analyses were conducted by study location (U.S., Europe, and others), study quality (high versus low), mean sample size of the prospective study $(<20000$ versus $\geq 20000)$, parity of study population (primiparas versus multiparas), singleton pregnancy (yes versus no), and adjustment for potential confounders including maternal age, socioeconomic status/education, diabetes mellitus, chronic hypertension, body mass index, and gender of infant. Heterogeneity between subgroups was evaluated by meta-regression $[50,51,61]$.

Small study bias such as publication bias was evaluated with Egger's test [62] and Begg's test [63]. A $P$-value of 0.05 was used to determine whether significant publication bias existed. All statistical analyses were performed with Stata (version 12; StataCorp, College Station, TX). 


\section{ACKNOWLEDGMENTS}

JW, Q-JW and LW designed research; JW, Q-JW and LW conducted research; JW, T-TG, and Q-JW analyzed data; JW, C-XL, T-TG, Q-JW and LW wrote the draft; All authors read, reviewed and approved the final manuscript. Q-JW had primary responsibility for final content.

\section{CONFLICTS OF INTEREST}

The authors declare no competing financial interests.

\section{GRANT SUPPORT}

This study was supported by the Younger research fund of Shengjing Hospital (Grant 2014sj09 for Qi-Jun Wu) and the Natural Science Foundation of Shenyang (Grant F15-139-9-37 for Jun Wei).

Qi-Jun Wu was supported by the Fogarty International Clinical Research Scholars and Fellows Support Center at the Vanderbilt Institute for Global Health, funded by the Fogarty International Center, NIH, through an R24 Training Grant (D43 TW008313 to Xiao-Ou Shu).

\section{REFERENCES}

1. Steegers EA, von Dadelszen P, Duvekot JJ, Pijnenborg R. Pre-eclampsia. Lancet. 2010; 376:631-644.

2. Sibai B, Dekker G, Kupferminc M. Pre-eclampsia. Lancet. 2005; 365:785-799.

3. Roberts JM, Cooper DW. Pathogenesis and genetics of pre-eclampsia. Lancet. 2001; 357:53-56.

4. von Dadelszen P, Magee LA, Roberts JM. Subclassification of preeclampsia. Hypertens Pregnancy. 2003; 22:143-148.

5. Roberts JM, Hubel CA. The two stage model of preeclampsia:variations on the theme. Placenta. 2009; 30 Suppl A:S32-S37.

6. Arngrimsson R, Bjornsson S, Geirsson RT, Bjornsson H, Walker JJ, Snaedal G. Genetic and familial predisposition to eclampsia and pre-eclampsia in a defined population. Br J Obstet Gynaecol. 1990; 97:762-769.

7. Walsh SW. Maternal-placental interactions of oxidative stress and antioxidants in preeclampsia. Semin Reprod Endocrinol. 1998; 16:93-104.

8. Salihu HM, Wilson RE. Epidemiology of prenatal smoking and perinatal outcomes. Early Hum Dev. 2007; 83:713-720.

9. Levine RJ, Maynard SE, Qian C, Lim KH, England LJ, Yu KF, Schisterman EF, Thadhani R, Sachs BP, Epstein FH, Sibai BM, Sukhatme VP, Karumanchi SA. Circulating angiogenic factors and the risk of preeclampsia. N Engl J Med. 2004; 350:672-683.

10. Levine RJ, Lam C, Qian C, Yu KF, Maynard SE, Sachs BP, Sibai BM, Epstein FH, Romero R, Thadhani R, Karumanchi SA. Soluble endoglin and other circulating antiangiogenic factors in preeclampsia. $\mathrm{N}$ Engl J Med. 2006; 355:992-1005.

11. Ylikorkala O, Viinikka L, Lehtovirta P. Effect of nicotine on fetal prostacyclin and thromboxane in humans. Obstet Gynecol. 1985; 66:102-105.

12. Marcoux S, Brisson J, Fabia J. The effect of cigarette smoking on the risk of preeclampsia and gestational hypertension. Am J Epidemiol. 1989; 130:950-957.

13. Madazli R, Benian A, Aydin S, Uzun H, Tolun N. The plasma and placental levels of malondialdehyde, glutathione and superoxide dismutase in pre-eclampsia. J Obstet Gynaecol. 2002; 22:477-480.

14. Bainbridge SA, Sidle EH, Smith GN. Direct placental effects of cigarette smoke protect women from pre-eclampsia: the specific roles of carbon monoxide and antioxidant systems in the placenta. Med Hypotheses. 2005; 64:17-27.

15. Lisonkova $\mathrm{S}$, Joseph KS. Incidence of preeclampsia: risk factors and outcomes associated with early- versus late-onset disease. Am J Obstet Gynecol. 2013; 209:541-544.

16. Perni UC, Wikstrom AK, Cnattingius S, Villamor E. Interpregnancy change in smoking habits and risk of preeclampsia: a population-based study. Am J Hypertens. $2012 ; 25: 372-378$.

17. Stone CD, Diallo O, Shyken J, Leet T. The combined effect of maternal smoking and obesity on the risk of preeclampsia. J Perinat Med. 2007; 35:28-31.

18. Hammoud AO, Bujold E, Sorokin Y, Schild C, Krapp M, Baumann P. Smoking in pregnancy revisited: findings from a large population-based study. Am J Obstet Gynecol. 2005; 192:1856-1862, 1862-1863.

19. Basso O, Weinberg CR, Baird DD, Wilcox AJ, Olsen J. Subfecundity as a correlate of preeclampsia: a study within the Danish National Birth Cohort. Am J Epidemiol. 2003; 157:195-202.

20. Mortensen JT, Thulstrup AM, Larsen H, Moller M, Sorensen HT. Smoking, sex of the offspring, and risk of placental abruption, placenta previa, and preeclampsia: a population-based cohort study. Acta Obstet Gynecol Scand. 2001; 80:894-898.

21. Newman MG, Lindsay MK, Graves W. Cigarette smoking and pre-eclampsia: their association and effects on clinical outcomes. J Matern Fetal Med. 2001; 10:166-170.

22. Martin CL, Hall MH, Campbell DM. The effect of smoking on pre-eclampsia in twin pregnancy. BJOG. 2000; 107:745-749.

23. Odegard RA, Vatten LJ, Nilsen ST, Salvesen KA, Austgulen R. Risk factors and clinical manifestations of pre-eclampsia. BJOG. 2000; 107:1410-1416.

24. Xiong $X$, Wang FL, Davidge ST, Demianczuk NN, Mayes DC, Olson DM, Saunders LD. Maternal smoking and preeclampsia. J Reprod Med. 2000; 45:727-732.

25. Lindqvist $\mathrm{PG}$, Marsal K. Moderate smoking during pregnancy is associated with a reduced risk of preeclampsia. Acta Obstet Gynecol Scand. 1999; 78:693-697. 
26. Zhang J, Klebanoff MA, Levine RJ, Puri M, Moyer P. The puzzling association between smoking and hypertension during pregnancy. Am J Obstet Gynecol. 1999; 181:1407-1413.

27. Cnattingius S, Mills JL, Yuen J, Eriksson O, Salonen H. The paradoxical effect of smoking in preeclamptic pregnancies: smoking reduces the incidence but increases the rates of perinatal mortality, abruptio placentae, and intrauterine growth restriction. Am J Obstet Gynecol. 1997; 177:156-161.

28. Coonrod DV, Hickok DE, Zhu K, Easterling TR, Daling JR. Risk factors for preeclampsia in twin pregnancies: a population-based cohort study. Obstet Gynecol. 1995; 85:645-650.

29. Ioka A, Tsukuma H, Nakamuro K. Lifestyles and preeclampsia with special attention to cigarette smoking. J Epidemiol. 2003; 13:90-95.

30. England LJ, Levine RJ, Qian C, Morris CD, Sibai BM, Catalano PM, Curet LB, Klebanoff MA. Smoking before pregnancy and risk of gestational hypertension and preeclampsia. Am J Obstet Gynecol. 2002; 186:1035-1040.

31. Knuist M, Bonsel GJ, Zondervan HA, Treffers PE. Risk factors for preeclampsia in nulliparous women in distinct ethnic groups: a prospective cohort study. Obstet Gynecol. 1998; 92:174-178.

32. Sibai BM, Ewell M, Levine RJ, Klebanoff MA, Esterlitz J, Catalano PM, Goldenberg RL, Joffe G. Risk factors associated with preeclampsia in healthy nulliparous women. The Calcium for Preeclampsia Prevention (CPEP) Study Group. Am J Obstet Gynecol. 1997; 177:1003-1010.

33. England L, Zhang J. Smoking and risk of preeclampsia: a systematic review. Front Biosci. 2007; 12:2471-2483.

34. Conde-Agudelo A, Althabe F, Belizan JM, Kafury-Goeta AC. Cigarette smoking during pregnancy and risk of preeclampsia: a systematic review. Am J Obstet Gynecol. 1999; 181:1026-1035.

35. Zhang J, Yu KF. What's the relative risk? A method of correcting the odds ratio in cohort studies of common outcomes. JAMA. 1998; 280:1690-1691.

36. Cudmore M, Ahmad S, Al-Ani B, Fujisawa T, Coxall H, Chudasama K, Devey LR, Wigmore SJ, Abbas A, Hewett PW, Ahmed A. Negative regulation of soluble Flt-1 and soluble endoglin release by heme oxygenase-1. Circulation. 2007; 115:1789-1797.

37. Jeyabalan A, Powers RW, Durica AR, Harger GF, Roberts JM, Ness RB. Cigarette smoke exposure and angiogenic factors in pregnancy and preeclampsia. Am J Hypertens. 2008; 21:943-947.

38. Salafia C, Shiverick K. Cigarette smoking and pregnancy II: vascular effects. Placenta. 1999; 20:273-279.

39. Shah NR, Bracken MB. A systematic review and metaanalysis of prospective studies on the association between maternal cigarette smoking and preterm delivery. Am J Obstet Gynecol. 2000; 182:465-472.
40. England LJ, Grauman A, Qian C, Wilkins DG, Schisterman EF, Yu KF, Levine RJ. Misclassification of maternal smoking status and its effects on an epidemiologic study of pregnancy outcomes. Nicotine Tob Res. 2007; 9:1005-1013.

41. George L, Granath F, Johansson AL, Cnattingius S. Selfreported nicotine exposure and plasma levels of cotinine in early and late pregnancy. Acta Obstet Gynecol Scand. 2006; 85:1331-1337.

42. Gong TT, Wu QJ, Wang YL, Ma XX. Circulating adiponectin, leptin and adiponectin-leptin ratio and endometrial cancer risk: Evidence from a meta-analysis of epidemiologic studies. Int J Cancer. 2015; 137:1967-1978.

43. Jiao YS, Gong TT, Wang YL, Wu QJ. Comorbidity and survival among women with ovarian cancer: evidence from prospective studies. Sci Rep. 2015; 5:11720.

44. Gong TT, Wang YL, Ma XX. Age at menarche and endometrial cancer risk: a dose-response meta-analysis of prospective studies. Sci Rep. 2015; 5:14051.

45. Wu QJ, Li YY, Tu C, Zhu J, Qian KQ, Feng TB, Li C, Wu L, Ma XX. Parity and endometrial cancer risk: a meta-analysis of epidemiological studies. Sci Rep. 2015; 5:14243.

46. Stroup DF, Berlin JA, Morton SC, Olkin I, Williamson GD, Rennie D, Moher D, Becker BJ, Sipe TA, Thacker SB. Meta-analysis of observational studies in epidemiology: a proposal for reporting. Meta-analysis Of Observational Studies in Epidemiology (MOOSE) group. JAMA. 2000; 283:2008-2012.

47. Luan NN, Wu L, Gong TT, Wang YL, Lin B, Wu QJ. Nonlinear reduction in risk for colorectal cancer by oral contraceptive use: a meta-analysis of epidemiological studies. Cancer Causes Control. 2015; 26:65-78.

48. Luan NN, Wu QJ, Gong TT, Vogtmann E, Wang YL, Lin B. Breastfeeding and ovarian cancer risk: a metaanalysis of epidemiologic studies. Am J Clin Nutr. 2013; 98:1020-1031.

49. Wells, G. A., et al. The Newcastle-Ottawa Scale (NOS) for assessing the quality of nonrandomised studies in metaanalyses. Available from: http:/www.ohri.ca/programs/ clinical_epidemiology/oxford.asp. (Date of access: 12/ September/2015).

50. Gong TT, Wu QJ, Vogtmann E, Lin B, Wang YL. Age at menarche and risk of ovarian cancer: a meta-analysis of epidemiological studies. Int J Cancer. 2013; 132: 2894-2900.

51. Wu QJ, Yang Y, Vogtmann E, Wang J, Han LH, Li HL, Xiang YB. Cruciferous vegetables intake and the risk of colorectal cancer: a meta-analysis of observational studies. Ann Oncol. 2013; 24:1079-1087.

52. Wu QJ, Yang Y, Wang J, Han LH, Xiang YB. Cruciferous vegetable consumption and gastric cancer risk: a metaanalysis of epidemiological studies. Cancer Sci. 2013; 104:1067-1073. 
53. Wu QJ, Xie L, Zheng W, Vogtmann E, Li HL, Yang G, Ji BT, Gao YT, Shu XO, Xiang YB. Cruciferous vegetables consumption and the risk of female lung cancer: a prospective study and a meta-analysis. Ann Oncol. 2013; 24:1918-1924.

54. Greenland S. Invited commentary: a critical look at some popular meta-analytic methods. Am J Epidemiol. 1994; 140:290-296.

55. Greenland S, O'Rourke K. On the bias produced by quality scores in meta-analysis, and a hierarchical view of proposed solutions. Biostatistics. 2001; 2:463-471.

56. Greenland, S, O’ Rourke K. Meta-analysis. In: Modern Epidemiology, 3rd edn, (eds Rothman, K.J. et al.) 652-682. (Lippincott Williams \& Wilkins, 2008).

57. Higgins JP, Thompson SG. Quantifying heterogeneity in a meta-analysis. Stat Med. 2002; 21:1539-1558.

58. Hamling J, Lee P, Weitkunat R, Ambuhl M. Facilitating meta-analyses by deriving relative effect and precision estimates for alternative comparisons from a set of estimates presented by exposure level or disease category. Stat Med. 2008; 27:954-970.

59. Higgins JP, Thompson SG, Deeks JJ, Altman DG. Measuring inconsistency in meta-analyses. BMJ. 2003; 327:557-560.

60. DerSimonian R, Laird N. Meta-analysis in clinical trials. Control Clin Trials. 1986; 7:177-188.

61. Yang Y, Zhao LG, Wu QJ, Ma X, Xiang YB. Association between dietary fiber and lower risk of all-cause mortality: a meta-analysis of cohort studies. Am J Epidemiol. 2015; 181:83-91.

62. Egger M, Davey SG, Schneider M, Minder C. Bias in metaanalysis detected by a simple, graphical test. BMJ. 1997; 315:629-634.

63. Begg CB, Mazumdar M. Operating characteristics of a rank correlation test for publication bias. Biometrics. 1994; 50:1088-1101. 